\title{
Chilaiditi Syndrome: A Rare Cause of Shortness of Breath and Abdominal Pain
}

\author{
Muhammed Ekmekyapar, Muhammet Gökhan Turtay, Neslihan Yücel, Hakan Oğuztürk, Şükrü Gürbüz, Serdar Derya \\ Department of Emergency Medicine, Inonu University School of Medicine, Malatya, Turkey
}

Cite this article as: Ekmekyapar M, Turtay MG, Yücel N, Oğuztürk H, Gürbüz Ş, Derya S. Chilaiditi Syndrome: A Rare Cause of Shortness of Breath and Abdominal Pain. J Emerg Med Case Rep 2018; 9: 16-8.

\begin{abstract}
Introduction: Chilaiditi syndrome is a rare condition in which a segment of the small or large intestine is interposed in between the diaphragm and the liver. This case report presents a patient who was admitted to the Department of Emergency Medicine, Turgut Ozal Medical Center with complaints of respiratory distress and abdominal pain and then diagnosed with Chilaiditi syndrome.

Case Report: An 81-year-old female patient was admitted to the emergency department with complaints of difficulty in breathing and abdominal pain. The patient's anamnesis indicated that difficulty of breathing increased when she had abdominal pain. There was no defense or rebound, but sensitivity was observed on abdominal examination. Other system examinations were normal. Abdominal ultrasonography performed on the patient was also normal. A dynamic thorax-abdominal tomography was obtained in terms of differential diagnosis of the patient who had abdominal pain. In the dynamic thorax-abdominal tomography of the patient, loops of the colon were visualized in the vicinity of the liver anterior segment, and these images indicated with Chiliaditi syndrome.
\end{abstract}

Conclusion: As a result, when the causes of shortness of breath and abdominal pain are investigated, Chiliaditi syndrome should be considered as a differential diagnosis.

Keywords: Chilaiditi syndrome, abdominal pain, shortness of breath

Received: 30.05.2017 Accepted: 08.08.2017

\section{Introduction}

Chilaiditi's syndrome is a rare condition characterized by the interposition of the small or large (usually) intestinal loop between the diaphragm and the liver and usually diagnosed incidentally. It is typically asymptomatic, but it can be associated with symptoms ranging from intermittent, mild abdominal pain, nausea, vomiting, and loss of appetite; constipation; dyspnea; and chest pain (1). This case report presents a patient who was admitted to the emergency department with complaints of respiratory distress and abdominal pain and then diagnosed with Chilaiditi syndrome.

\section{Case report}

An 81 year-old-female patient was admitted to the emergency department with a 24-h shortness of breath and abdominal pain. She had chronic obstructive pulmonary disease previously. On examination of her vital signs, her blood pressure was 123/87 $\mathrm{mmHg}$, heart rate was 110 beat/min, respiratory rate was $15 / \mathrm{min}$, fever was $36^{\circ} \mathrm{C}$, and oxygen saturation was $96 \%$. Physical examination revealed distension and diffuse abdominal tenderness, but there was no rigidity and rebound tenderness. The other system examination findings were all normal. 


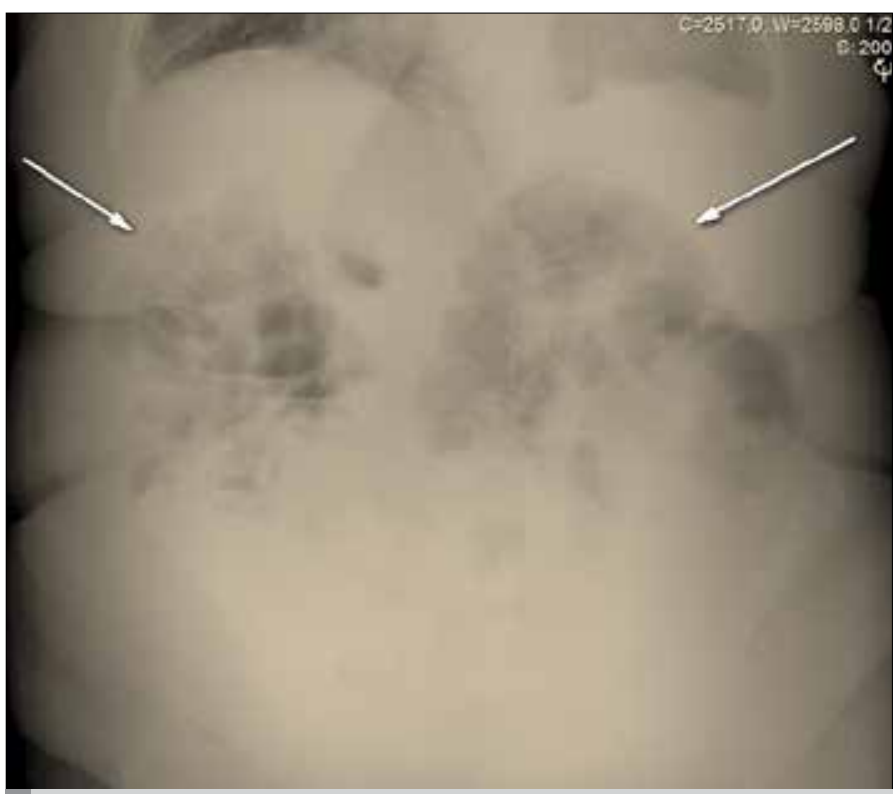

FIGURE 1. Colonic gases on plain abdominal radiography

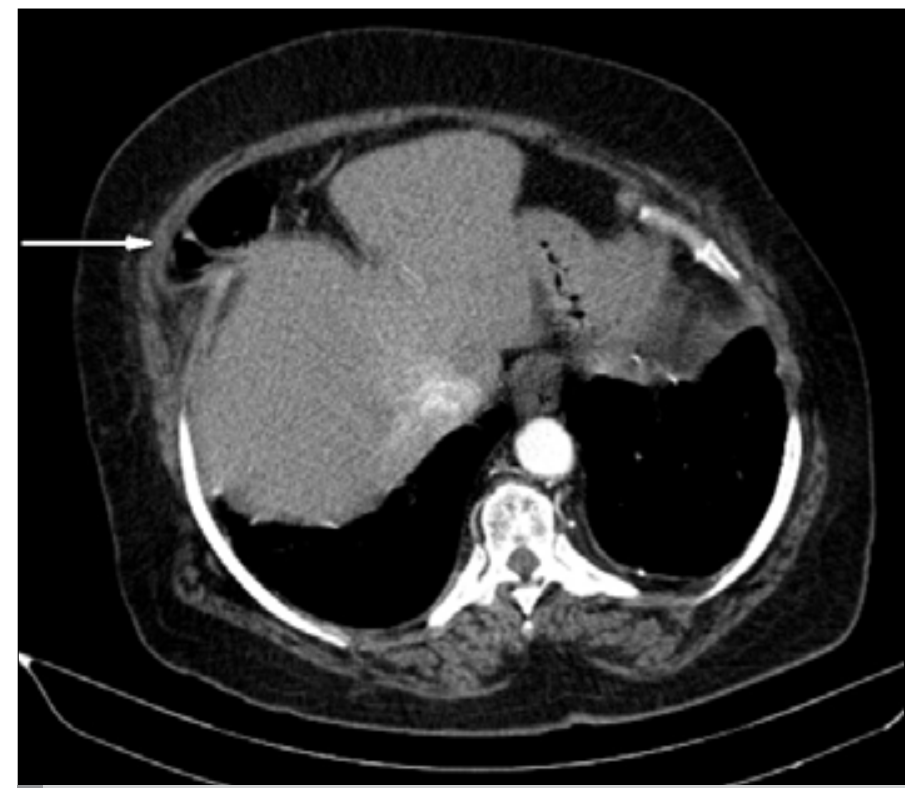

FIGURE 2. Loops of the colon observed between the liver and the right hemi diaphragm on abdominal computed tomography

Complete blood count and blood biochemistry were within the normal range except for the following: aspartate aminotransferase, $65 \mathrm{U} / \mathrm{L}$; alanine aminotransferase, $81 \mathrm{U} / \mathrm{L}$; gamma-glutamyltransferase, $112 \mathrm{U} / \mathrm{L}$; and lactate dehydrogenase, $475 \mathrm{U} / \mathrm{L}$. Arterial blood gases and D-dimer were within the normal range. Plain chest and direct abdominal radiography and abdominal ultrasonography (USG) were performed. Only some colonic gases were observed on direct abdominal X-ray (Figure 1). A dynamic thorax and abdominal computed tomography (CT) was performed for differential diagnosis. It demonstrated gas-filled proximal transverse colonic lumen between the right hemi diaphragm and the liver (Chilaiditi sign) (Figure 2), and it was reported as Chiliaditi syndrome by the radiolo- gist. The patient's complaints were relieved with intravenous fluids and bowel decompression, and she was discharged after 2 days of follow-up.

\section{Discussion}

Chilaiditi syndrome was first defined as a hepatodiaphragmatic interposition of the colon or small bowel by a Viennese radiologist named as Demetrius Chilaiditi in 1910 (2). The incidence increases with age, and the male/female ratio is $4 / 1$ (3). This syndrome is a rare condition and is diagnosed incidentally. In the literature, it has been reported between $1.18 \%$ and $2.40 \%$ with abdominal CT and between $0.025 \%$ and $0.280 \%$ in plain chest and abdominal films (4).

Chilaiditi syndrome is usually asymptomatic, but it can have numerous clinical symptoms, such as abdominal pain, distention, nausea, vomiting, flatulence, changes in bowel habits, chest pain, arrhythmia, shortness of breath, and respiratory distress (4). Our patient was admitted to the emergency department with abdominal pain and shortness of breath.

Chilaiditi syndrome may possibly lead to unnecessary exploratory laparotomies with a confusion of such cases as diaphragmatic hernia, subdiaphragmatic abscesses, or bowel perforation (5). Differential diagnosis of perforation of the hollow viscus organ, which is an emergency situation, should be made in the presence of right infradiagraphmatic air. CT is very important for confirming and differential diagnosis (6). The differential diagnosis of other diseases was made before the diagnosis of this syndrome in this case, and the diagnosis of the patient was determined by abdominal CT.

Conservative treatment is provided for symptoms of the disease, but surgical intervention is indicated when life-threatening complications occur (7). This syndrome, which is usually benign, can progress and even lead to death (7). In the present case, conservative treatment was performed after the diagnosis of Chiliaditi syndrome, and the patient was discharged after her symptoms were resolved.

\section{Conclusion}

It is very important to distinguish between the diseases that require urgent intervention, particularly perforation of the hollow viscus organ, and Chilaiditi syndrome so that unnecessary examinations and surgical interventions are not performed on the patients. As a result, while the causes of shortness of breath and abdominal pain are investigated, Chiliaditi syndrome should be considered as a differential diagnosis.

Informed Consent: Written informed consent was not obtained from the patient.

Peer-review: Externally peer-reviewed.

Author Contributions: Concept - M.E., M.G.T., N.Y.; Design - M.E., H.O.; Supervision - M.G.T., H.O.; Data Collection and/or Processing - N.Y., Ş.G., S.D.; Analysis and/or Interpretation - H.O., S..G., S.D.; Literature Search - M.G.T.; Writing Manuscript - M.E., Ş.G.; Critical Review - N.Y., S.D. 
Conflict of Interest: No conflict of interest was declared by the authors.

Financial Disclosure: The authors declared that this study has received no financial support.

\section{References}

1. Nair N, Takieddine Z, Tariq H. Colonic Interposition between the Liver and Diaphragm: The Chilaiditi Sign. Can J Gastroenterol Hepatol 2016; 2016: 1-2. [CrossRef]

2. Chilaiditi D. Zurfrage der hepatoptose und ptoseimallgemeinenimanschluss an dreifalle vontemporarer, partiellerleberverlagerung. FortschrGebRontgenstr 1910; 16: 173-208.
3. Kaya H, Gökdemir MT, Söğüt Ö, Terzi A, Dokuzoğlu MA. Chilaiditi Syndrome in a Young Patient. JAEMCR 2013; 4: 44-6. [CrossRef]

4. Takahashi K, Ito H, Katsube T, Tsuboi A, Hashimoto M, Ota E, et al. Treatment of Chilaiditi syndrome using laparoscopic surgery. Asian J Endosc Surg 2017; 10: 63-5. [CrossRef]

5. Risaliti A, De Anna D, Terrosu G, Uzzau A, Carcoforo P, Bresadola F. Chilaiditi's syndrome as a surgical and nonsurgical problem. Surg Gynecol Obstet 1993; 176: 55-8.

6. Guerra F, Sacchetti R. Chilaiditi syndrome. An uncommon cause of crampy, upper abdominal pain. Ann Hepatol 2016; 15: 773-4.

7. Fomin D, Baranauskaite V, Laima S, Jasulaitis A, Petroška D. Death Caused by Hepatodiaphragmatic Interposition of the Colon. J Forensic Sci 2017; 62: 247-9. [CrossRef] 